\title{
Lycopodiaceae endémicas del Perú
}

\section{Blanca León ${ }^{1,2}$}

${ }^{1}$ Museo de Historia Natural Av. Arenales 1256, Aptdo. 14-0434, Lima 14, Perú

2 Plant Resources Center, University of Texas at Austin, Austin TX 78712 EE.UU.

blanca.leon@mail.utexas.edu

\section{Resumen}

Esta familia es reconocida en el Perú con tres géneros y 65 especies (Øllgaard, 1994; Smith et al., 2005). Solamente el género Huperzia incluye siete endemismos para la flora peruana. La mayoría de estas especies son plantas terrestres que ocupan principalmente las regiones del Bosque Pluvial Montano, la Puna Seca y Húmeda y Páramo. Dos de los endemismos están representados en áreas protegidas.

Palabras claves: Lycopodiaceae, Perú, endemismo.

\section{Abstract}

This family is recognized in Peru with three genera and 65 species (Øllgaard, 1994; Smith et al., 2005). Only the genus Huperzia includes seven endemics for the Peruvian flora. These species are mostly terrestrial plants occurring in Pluvial Montane Forest, Dry and Humid Puna, and Paramo regions. Two endemic species are found in protected areas.

Keywords: Lycopodiaceae, Peru, endemism.

\section{Huperzia colanensis B. Øllg.}

\section{Huperzia binervia (Herter) Holub}

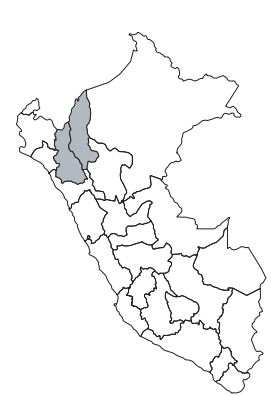

\section{VU, B1ab(iii)} $2380-2600 \mathrm{~m}$.

SINANPE: PNC
Publicación: Opera Bot. 92: 169. 1987.

Colección tipo: A. Mathews s.n.

Herbarios: BM, GL, K, P.

Nombre común: Desconocido.

Registro departamental: AM, CA.

Regiones Ecológicas: PAR, BMHM;

Herbarios peruanos: HUT (1), USM (4).

Observaciones: Hierba terrestre conocida solamente del norte del país. Al menos una población es conocida de un área protegida, pero fuera de ella es probablemente amenazada por modificación de hábitat debido a incendios intencionales. Esta especie se conoce de humedales y pajonales en ambientes ecotonales de bosque y páramo.

\section{Huperzia buesii (Herter) B. Øllg.}

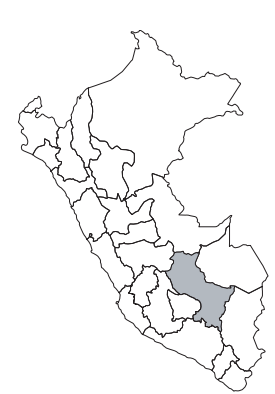

Publicación: Fieldiana Bot., n.s. 34: 42. 1994.

Colección tipo: C. Bües 742

Herbarios: US; CUZ!.

Nombre común: Desconocido.

Registro departamental: CU.

Regiones Ecológicas: BMHM; $1800 \mathrm{~m}$.

SINANPE: Sin registro.

Herbarios peruanos: CUZ (isotipo).

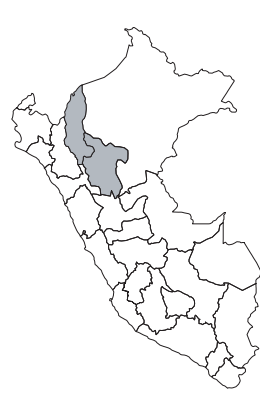

EN, B1ab(iii)

Publicación: Fieldiana Bot., n.s. 34: 31. 1994.

Colección tipo: P.J. Barbour 3384

Herbarios: AAU, MO; USM!.

Nombre común: Desconocido.

Registro departamental: AM, SM.

Regiones Ecológicas: BPM; 3200—3300

m.

SINANPE: PNRA, ZRCC

Herbarios peruanos: USM (isotipo).

Observaciones: Hierba erecta, rara, conocida de ambientes ecotonales bosque-pajonal en el norte del país. Aparentemente no ha vuelto a ser recolectada desde 1978. Una población fue hallada en una localidad que hoy forma parte del Parque Nacional Río Abiseo; sin embargo, no ha vuelto a ser hallada en esa localidad durante expediciones entre 1999 y 2001.

\section{Huperzia engleri (Herter) B. Øllg.}

Observaciones: Esta especie epífita fue considerada por Øllgaard (1994) una endémica rara, por conocerse de sólo dos colecciones de Cusco. Aparentemente no ha vuelto a ser recolectada desde la década de 1950. Podría estar en bosques remanentes en el valle de la Convención, aunque, por el rango altitudinal de la que se la conoce, podría estar amenazada por la expansión agrícola.

\section{EN, B1ab(iii)}

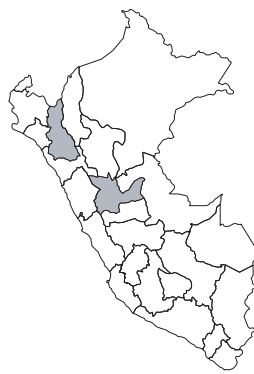

Publicación: Opera Bot. 92: 169. 1987. Colección tipo: A. Weberbauer 3359

Herbarios: B, BONN; MOL!

Nombre común: Desconocido.

Registro departamental: CA, HU.

Regiones Ecológicas: PSH, BPM; 3200$3300 \mathrm{~m}$

SINANPE: Sin registro.

Herbarios peruanos: MOL (isotipo).

Observaciones: Hierba palustre conocida solamente de dos localidades aisladas, una en la cuenca alta del Monzón y otra en una subcuenca del Marañón. Aparentemente no ha sido recolectada desde 1903. Por su hábitat pantanoso, naturalmente fragmentado, sus poblaciones podrían estar afectadas por sequía e incendios. 


\section{Huperzia nessellii (Brause ex Nessel) Rolleri \& Deferrari}

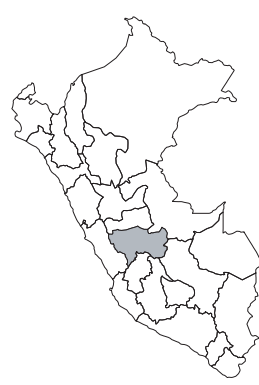

\section{CR, B1ab(iii)}

Publicación: Notas Mus. La Plata, Bot. 21(100): 156. 1988.

Colección tipo: A. Weberbauer 2222

Herbarios: BONN; MOL!.

Nombre común: Desconocido.

Registro departamental: JU.

Regiones Ecológicas: PSH; 3400—3500

$\mathrm{m}$.

SINANPE: Sin registro.

Herbarios peruanos: MOL (isotipo).

Observaciones: Esta hierba terreste está limitada en distribución al centro del Perú, se conoce de una localidad herborizada a inicios del siglo XX, en la cuenca del Palca. Øllgaard (1994) considera que todo el material citado corresponde a la colección de A. Weberbauer realizada en Junín, pero no en Cusco como citó Nessel.

\section{Huperzia pruinosa (Herter) Holub}

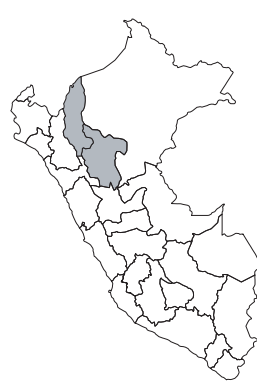

\section{EN, B1ab(iii)}

Publicación: Folia Geobot. Phytotax. 20: 76. 1985.

Colección tipo: A. Weberbauer 4410

Herbarios: B, BONN, G.

Nombre común: Desconocido.

Registro departamental: AM, SM.

Regiones Ecológicas: BMHM; 1900$2600 \mathrm{~m}$.

SINANPE: Sin registro.

Herbarios peruanos: Ninguno.

Observaciones: Esta especie terrestre se conoce de tres localidades en el nor-oriente del país. La localidad original no ha vuelto a ser herborizada desde inicios del siglo XX. Poco se sabe de las características de su hábitat, aunque por describírsele como terrestre escandente en bosque, sus poblaciones podrían estar amenazadas por la deforestación.

\section{Huperzia sagasteguiana B. Øllg.}

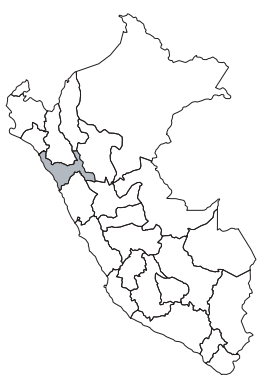

CR, B1ab(iii)

Publicación: Fieldiana Bot., n.s. 34: 37. 1994.

Colección tipo: A. López M. \& A. Sagástegui A. 8177

Herbarios: AAU, GH, MO, NY; HUT.

Nombre común: Desconocido.

Registro departamental: LL.

Regiones Ecológicas: PAR; $3900 \mathrm{~m}$.

SINANPE: Sin registro.

Herbarios peruanos: HUT (isotipo+1).

Observaciones: Esta hierba terrestre se conoce de sólo una localidad en el nor-oriente del país. Por su hábitat y hábito puede que pase desapercibida, aunque la zona que habita tiene fuerte impacto de ganadería y minería. 